\title{
Competency Development for Safety Measures on Roads as a Strategy for Prevention of Traffic Accidents
}

\author{
Rosa Sh. Akhmadieva \\ Kazan (Volga region) Federal University, 420008, Kazan, Russia \\ Email: roza79.08@mail.ru
}

\section{Doi:10.5901/mjss.2015.v6n2s3p176}

\begin{abstract}
Traffic safety is not only a component of the protection of life and health of people and their property but also a public good being an aggregate of material and spiritual values related to provision of traffic safety. A purpose of this article is to develop a methodological framework for the competency development with teachers-to-be regarding safety measures on roads. The major approach to the investigation of the problem in question is a modular competency-based approach. The most efficient forms of development of the competency in safety measures on roads with professionals-to-be are as follows: didactic games; variable test-drives; simulator-based practice; case studies on problems of safety measures on roads; development and implementation of academic educational and industrial projects regarding safe behavior on roads, arrangement and implementation of special contests or events focusing on safe behavior on roads. The materials of this article can be used to elaborate educational courses for professionals-to-be in the field of "health and safety", as well as to develop Republic-wide target programs focusing on improvement of the traffic safety and the federal target program for the improvement of the traffic safety till 2020.
\end{abstract}

Keywords: health and safety on roads, competency development, methodological framework, modular competency-based approach.

\section{Introduction}

At present, personal health and safety on roads is one of global values of the mankind. It is conditioned with potential hazards of the traffic and the process of its intensification for individuals and for the society. Hence, the necessity occurs to develop awareness, skills and experience of safe behavior on roads with people. The implementation of this objective has necessitated training of professionals for provision of health and safety on roads within the pedagogical education system: it is necessary to develop competency in health and safety on roads with higher-education institutions graduates specializing in the profession 033300 "Health and Safety" qualified as health and safety instructors. The training of the professionals-to-be in the field of health and safety is carried out based on special educational programs approved by the Ministry of Education and Science and agreed with the Ministry of Interior and the Ministry of Emergency Situations of the Russian Federation. The training of the professionals-to-be under such programs ensures integration of awareness and skills in a unified system that conditions development of new competencies vital to preserve the life in the $21^{\text {st }}$ century, one of such competencies being the awareness of the health and safety on roads. (Borovsky, 1984; Belkova, 1994; Belov, 2000). The structure of this competency comprises theoretical knowledge of factors, essence and structure of traffic safety; skills and abilities to identify and prevent hazards or threats on the road capable of inflicting irreparable harm (damage) to vital interests of an individual, as well as to ensure personal and public safety on the road.

Analysis of the national experience in in the field of traffic provision enabled to identified the following crucial conditions for the development of an individual's safe behavior on the road: development of regulatory and legal framework including federal and regional laws, decrees of the President of Russia, decrees of the Government of Russia, federal target program "Improvement of traffic safety in 2006-2012"; higher activity of departments and committees in charge of the traffic safety throughout the "managerial vertical"; arrangement of information and propaganda work aiming to improve legal awareness, focusing of public attention on the matters of traffic safety, learning basic ideas on hazardous situations on the road and their effect on the individual's life and health; energizing of work with children, adolescents and youths in order to train the rules of safe behavior on the road; improvement of control and supervision activities regarding the provision of the traffic safety (Akhmadiyeva, 2011; Alekhin, 2010).

Analysis of the foreign experience in in the field of traffic provision proved that in order to develop and individual's safe behavior on the road, the following conditions are to be met: speed management; complete inadmissibility of drunk driving; application of seatbelts; better roads quality; improvement of structural safety of vehicles; lower risks for beginner 
drivers; insurance of vehicles and the driver's and passengers' health; development of preventive programs (regarding safe transportation of children to and from the school, safe operation of the public transport and cargo transportation on roads); development of the NCAP (New Car Assessment Program) information program; hosting of the Traffic Safety Week upon resolutions of the UN in member countries.

\section{Materials and Methods}

The main approach for the investigation of the problem of developing the competency in the health and safety on roads with professionals-to-be in the field of health and safety is a modular competency-based approach considered by the author as correlative to systematic, integrative, differentiated, acmeological, contextual approaches, a special training of professionals-to-be under the condition of integration of education, science and industry that conditions development of their alacrity to efficiently perform their professional objectives (Moshkina, 2002; Yakupov, 2007; Telegina et al., 2015; Khairullina et al., 2015). It was established that as a part of a training practice, the modular competency-based approach conditions development of competency models with graduates of professional schools. The graduates are to possess the aggregate of knowledge and competencies that ensure not only a performance of their labor functions in the contemporary information- and technology-based environment, but also an ability to develop it as applicable to a certain project, to quickly adapt to external alterations of the environment, to identify and to allot problems and to solve challenging matters.

The following criteria are highlighted in the article as basic principles for development of health and safety on the road being the competency of the professionals-to-be:

- participative principle that implies various forms of social partnership between professional education institutions and ministries, departments and committees in charge of arrangement and safety of traffic in the process of development of the traffic health and safety as a competency of the professionals-to-be, and regulates the update of the development contents of such competency considering alterations of traffic rules;

- continuity principle that conditions systematic integrity of special events ("Green Light", "Traffic Science School", "School bus", "Autosession", "Autolady", etc.) and training programs on basics of traffic health and safety in the vertical and horizontal structure of the training process; development of the willingness to learn for the whole life with the trainees ("life-long education");

- cluster principle aiming to integrate target, incentive, contensive, activity-based, and reference and qualificatory components of the pedagogical process for the development of the traffic health as safety as a competency of the professionals-to-be;

- productivity principle that ensures development of willingness to behave safely on the road with the professionals-to-be by means of their participation in development and implementation of scientific educational and industrial projects in the field of traffic health and safety (rallies of young traffic inspectors; development and implementation of automatic video enforcement systems for traffic rules violations; development of the transport infrastructure; assistance to victims to traffic accidents; development of awareness-raising and educational web-sites focusing on the traffic safety; activities of go-cart clubs, etc.);

- personification principle that conditions integrated and deliberate impact on development of personality features; development of sustainable, conscious and positive attitude to the traffic safety; identification of a personal development trajectory for elaboration of the traffic health and safety competency for each professional-to-be;

- preclusiveness principle which means prevention of reckless behavior of road users; development of preventive programs and arrangement of awareness-raising and propaganda work in order to ensure traffic health and safety.

The aggregate of the above-mentioned principles ensures systematic integrity of contents, forms, methods and conditions for the process of development of the traffic health and safety as a competency of the professionals-to-be.

The basic methods for the investigation of the problem of development of the traffic health and safety competency are as follows:

- theoretical methods (scientific analysis of the professional literature and training material for the problem in question, studying and summary of the pedagogic experience regarding the subject of the research, contents analysis, cluster analysis, modeling);

- social and pedagogic methods (observation, questioning, conversations, test exams, expert evaluation, event analysis, monitoring, action research, role-play and business games, comparison of current statements and 
arguments of the professionals-to-be to previous ones);

- experimental methods (variable-based test-drives, simulator-based training, summative cross-section, arrangement and performance of a formative experiment);

- statistical analysis and conceptual interpretation of the research results, their mathematical processing and grouping.

\section{Results}

It was found that innovative methodological framework for development of the traffic health and safety competency with the professionals-to-by is an aggregate of especially arranged interaction of subject of the pedagogical process and methodological study aids that define objectives, stages, forms, methods and criteria of making the professionals-to-be ready to fulfill tasks related to the manifestation of such competency in the field of the traffic safety.

Quality of the innovative methodological study aids is an indicator of the methodological culture of instructors and their pedagogical creativity. On the one hand, instructors of the higher education are practice-focused professionals that influence the professional-to-be with their personality features, scientific achievements, and combine the arrangement of the educational process with scientific research. On the other hand, the instructor is the lead subject of the educational process that interacts with the professionals-to-be on the basis of humanistic education principles in order to train competitive professionals and to shape the personality of the trainees. The following can be highlighted as components of the methodological culture: mastering the methodological (general scientific and psychological pedagogical) knowledge and the ability to actively apply it in the professional activities, focus on social values, and autopsychological attitude.

It was further established that generation of the professional training system on an integrative basis (integration of educational institutions with the science and industry; integration of training forms and methods; integration of common and professional knowledge; integration of theory and practice; integration of didactic concepts; subject-oriented and target integration of disciplines within scientific, social, humanitarian and professional cycles; subjective integration; integration of generation of professional and personal competencies with that in the traffic health and safety) conditions generation of a comprehensive idea of the traffic health and safety, recognition of priority of the traffic rules observation, sustainable attitude of the personality towards safe behavior on the road, generation of alacrity for proactive actions to prevent hazards or threats.

The informative episodic environment is defined as a multi-dimensional and polyfunctional surrounding of the subjects of the pedagogical process that impacts the generation of belief foundations for contemporary problems of vital activities, responsible and respectful attitude towards personal and public safety, resilience in hazardous or threatening situation occurring on the road with the professionals-to-be, as well as obtaining skills and experience for the provision of the traffic health and safety. The informative component of the environment shapes the subject field for the traffic health and safety. The episodic component conditions arrangement of a dynamic grid of interlinked events that apply a regulatory impact to the understanding of the necessity to prevent hazards and threats on the road that may inflict irreparable harm (damage) to an individual's vital interests; attitude towards the personal and public safety; the ability to adequately respond to various hazardous situations taking their abilities into account. The events that fall within the field of perception of the specialist-to-be serve as a subject to assessment, food for thought and grounds for vital conclusions.

Creation of an interactive social infrastructure considering pedagogical requirements implies arrangement of a system of efficient interaction between social and pedagogic institutions and the Traffic Police, public organizations, ministries and departments interested in generation of the traffic health and safety competency with the professionals-tobe in order to integrate educational, professional, project-based and extra-curricular activities of the professionals-to-be. The interactive nature of the social infrastructure is conditioned with application of such forms of training as variablebased test-drives, practical training on simulators, participation in activities of driving schools and go-cart clubs, monitoring of the public opinion regarding the traffic safety, contest and events in the process of developing the safe behavior on the road.

The experimental work to generate the traffic health and safety competency with the professionals-to-be was carried out from 2009 to 2014. The experimental group was comprised of 48 instructors working at the physical training and 270 professionals-to-be trained for the profession 033300 "Health and safety" to be qualified as "Instructor for health and safety" in the Kazan (Volga) Federal University.

In the course of the experiment, the following was implemented: didactic aid "Safety on the road and in public transport", multimedia didactic aid "ABC of traffic science", methodological study aid for generation of traffic health and safety competency with the professionals-to-be "Teaching the rules of safe behavior on the road", methodological recommendations to arrange the monitoring of the public opinion regarding traffic safety problems and panel talks "Safety 
as seen by the youth", variable-based test-drives, electronic information media for propaganda of safe behavior on the road for various ages, computer games "Rules of behavior on the road", a kit of didactic materials for prevention of injuries in traffic accidents, methodological recommendations to attract the professionals-to-be to driving schools and gocart clubs, arrangement of practical training on simulators, hosting special contests and events ("Attention: children!", "Attention: pedestrians!", "Polite driver", "Crosswalk", "Safe wheels", "Green light", "Help the first-grader get to school safe", "Traffic Science School", "Autosession"), a commemorative event for victims of traffic accidents, driver's handbook, case study for independent learning of traffic rules and mastering of skills and abilities to secure the traffic health and safety.

Table 1. Development dynamics for alacrity for professional activities focused on generating the traffic health and safety competency with professionals (\%)

\begin{tabular}{|c|c|c|c|}
\hline Item & $\begin{array}{l}\text { Major indicators of future professionals' alacrity for the professional activities } \\
\text { focused on generating the traffic health and safety competency. }\end{array}$ & $\begin{array}{l}\text { Before the } \\
\text { experiment }\end{array}$ & $\begin{array}{l}\text { After the } \\
\text { experiment }\end{array}$ \\
\hline & Motivational alacrity & & \\
\hline 1 & $\begin{array}{l}\text { Willingness to work with children and adolescents to develop safe behavior on } \\
\text { the road }\end{array}$ & 45 & 85 \\
\hline \multirow[t]{2}{*}{2} & Interest in the discipline "Safety on the road and in public transport" & 60 & 80 \\
\hline & Research activities & & \\
\hline 3 & $\begin{array}{l}\text { Participation in scientific seminars, conferences highlighting the problems of the } \\
\text { traffic safety }\end{array}$ & 0 & 13 \\
\hline 4 & Publications on the problems of the traffic safety & 0 & 5 \\
\hline \multirow[t]{2}{*}{5} & $\begin{array}{l}\text { Participation in arrangement and hosting contests or events related to the } \\
\text { promotion of rules of safe behavior on the road }\end{array}$ & 4 & 83 \\
\hline & Methodological alacrity & & \\
\hline 6 & $\begin{array}{l}\text { The ability to arrange the activities intended for mastering the knowledge, skills } \\
\text { and abilities of safe behavior on the road }\end{array}$ & 54 & 75 \\
\hline 7 & Knowledge of basics of health and safety on the road & 4 & 15 \\
\hline 8 & $\begin{array}{l}\text { The ability to assess current and final results of activities intended for mastering } \\
\text { the knowledge, skills and abilities of safe behavior on the road }\end{array}$ & 37 & 70 \\
\hline
\end{tabular}

\section{Discussions}

The theoretical basis of safety is a subject to research works of foreign (Aron, 1992; Kissinger, 2014; Lippman, 2004; Waltz, 1985 and others) and Russian sciences (Alekhin, 2010; Vasilyeva, 1999; Belkova, 1994; Glebova, 1999; Demin, 1976; Osipova, 1990; Pershina, 2006; Subetto, 1997; Ursula, 1996 and others).

I.A.Alekhin (2010), developed new approaches to the improvement of the methodology and theory of safety of life sustenance systems in the contemporary education; he elaborated the didactic ideas on the matters of social and pedagogic support for the safety of trainees; he developed innovative safety technologies in the education system. He also defined theoretical methodological and applied pedagogical provisions in the development of the theory of safety of educational systems; I.A.Alekhin (2010) identified the role of military education in the provision of safety of educational systems in the Russian Federation.

Sociological researches in the field of safety were performed by such scientists as, W.Beck, (2000); E.Giddens, (1994); N.V.Kuznetsov, (2000); N.R.Malikova, (1992); A.AProkhozhev, (2002); P.Shtompka, (2005) and others. Safety within the context of coevolutional and sustainable development was considered by E.IGlushenkova, (2004); V.I.DanilovDanilyan, (1999); S.I.Doroguntsov, (2002), and other. Mechanisms of generating the culture of safety are highlighted in research works by V.V.Anisimova, (2006); O.G.Grokholskaya, (2010); V.N.Moshkina, (2002) and others. Methods of teaching the basics of health and safety are elaborated in the works of S.V.Belov, (2000); A.V.llyitskaya, (2007); A.F.Kozyakov, (2007); A.T.Smirnov, (2009) and others. A regional system for prevention of injuries in traffic accidents was substantiated by R.N.Minnikhanov, (2003); I.A.Khaliullin, (2003); L.G.Akhmetshina, (2003). The process of generating the transport culture and safety on the road was researched by B.E.Borovsky, (1984); I.A.Korshakov, (1988) and A.M.Yakupov, (2007).

However, methodological foundations for generating the idea of health and safety on the road as a competency of a pedagogue-to-be are not sufficiently elaborated in the research literature. 


\section{Conclusion}

Taking the above into consideration, introduction of the basics of the traffic health and safety based on the modular competency-based approach to the professional training of the professionals-to-be in the field of "Health and safety" is necessitated both with an increase in numbers of traffic accidents and the role of the human factor in them.

The essence of an individual's health and safety on the road consists in being protected against hazards or threats capable of inflicting irreparable harm (damage) to the individual's vital interests.

The structure of the health and safety on the road includes comprehensive understanding of the health and safety on the road, responsible and respectful attitude to personal and public safety, the alacrity to carry out proactive acts to prevent the hazards or threats, the abilities and skills of securing the health and safety on the road taking one's capabilities into account.

The contents of an individual's health and safety on the road ensures development of the competency in this field with the professionals-to-be that reflects cognitive, dispositional and perceptive personality features and not only conditions the development of the willingness to behave safely on the road but also influences their public and moral attitude, social identity and self-perfection, and the way of life.

The experimental work focusing on development of the competency in the health and safety on the road with the professionals-to-be proved that the most efficient are the integrated forms of training (didactic games, variable-based test-drives, practical training on simulators, case studies on the problems of the traffic health and safety, development and implementation of educational and industrial projects regarding the safe behavior on the road), introduction of the modular competency-based training course "Safety on the road and in public transport" to the contents of the training, arrangement and hosting of special contests or events focusing to the safe behavior on the road that promote the apprehension of the necessity to prevent hazards and threats on the road that may inflict irreparable harm to an individual's vital interests and also develop the willingness to behave safely on the road and to consider their capabilities with the professionals-to-be.

\section{Recommendations}

The materials of this article can be used to perfect training courses within the training system for the professionals-to-be in the field of "Health and safety", as well as for development of Republic-wide target programs focused on improvement of the traffic safety and the Federal target program for the improvement of the traffic safety till 2020.

\section{References}

Akhmadiyeva, R. Sh.(2011). Development of the traffic health and safety competency in the process of continuous education. Economic and humanitarian researches in regions:2, $49-54$.

Akhmadiyeva, R. Sh. (2011). Development technology for the traffic health and safety competency with the pedagogue-to-be. Bulletin of Kazan State Technological University: 7, 259-267.

Akhmadiyeva, R. Sh. (2011). Health and safety on the road as a competency of the graduate of the pedagogy. Economic and humanitarian researches in regions: 3, 35-43.

Akhmetshina, L. G., Khaliullina, I. A. \&Minnikhanov, R. N. (2003). Regional system of prevention of child road traffic injuries in the Republic of Tatarstan. Kazan, 160.

Alekhin, I. A. (2010). Didactic principles of life safety. World of Education - education in the world: 3 (39), 3-8.

Anisimov, V. V., Grokholsky, O. G., \& Nikandrov, N. D. (2006). General foundations pedagogy. Moscow: Education, 574.

Aron, R. (1992). Stages of development of sociological thought. Moscow: Publishing Group "Progress" - "Politics", 608.

Beck, W. (2000). Risk Society. Moscow: Progress in tradition, 384.

Belkova, O. A. (1994). The general theory of security (A. I. Pozdnyakova). Moscow: VAGSH, 289.

Belov, S. V. (2000). Heath and safety. Moscow: Higher. wk., 243.

Borovsky, B. E. (1984). Traffic safety of road transport. Analysis of road accidents "Lenizdat", 330.

Danilov-Danilyan, V. I. Osipov, V. \& Makhutov, N. A. (1999). Security in Russia: legal, socio-economic and scientific-technical aspects.

Demin, M. V. (1976). Principle as a form of scientific knowledge. Moscow: State University, 44.

Doroguntsov, S. I. (2002). Management of technogenic and ecological safety in the context of sustainable development paradigm: the concept of system-dynamic solutions. Kiev: Naukova Dumka, 200.

Giddens, E. (1994). Fate, risk and safety. Thesis:5, 407.

Glebova, I. N. (1999). Legal problems of national security of the Russian Federation (Doctoral dissertation). Moscow, 330.

Glushenkova, E. I. (2004). Sustainable development as a conceptual framework for the national security strategy of Russia. Moscow: IMEMO. 
Grokholskaya, O. G. (2010). Building a culture of safety of the younger generation in modern Russian society. Vestn. Univ of radioactive waste: $1,138-145$

Ilyitskaya, A. V, Belov, S. V., Initskaya, A. V. \& Koziakov, A. F. (2007). Health and Safety. Moscow: Higher School, 616.

Khairullina E.R., Valeyev A.S., Valeyeva G.K., Valeyeva N.S., Leifa A.V., Burdukovskaya E. A., Shaidullina A.R. (2015). Features of the Programs Applied Bachelor Degree in Secondary and Higher Vocational Education. Asian Social Science; Vol. 11, No. 3, 213217, doi:10.5539/ass.v11n4p213.

Kissinger, H. (2014). World Order. New York: Penguin Press.

Korshakov, I. A. (1988). Vehicles and pedestrians. Moscow, 362.

Kuznetsov, N. V. (2002). Sociology of security: Building a Culture of Safety in a transforming society. Moscow: Republic, 29.

Lippman, W. W. (2004). Lippmann Public opinion (T. Barchunova, K. A. Levinson, \& K. V. Petrenko). Moscow: Institute Foundation "Public Opinion", 384.

Malikova, N. R. (1992). Paradoxes ethnic obscheniyayu. Moscow.

Moshkina, V. N. (2002). Technology education culture safety of school children in the learning process. http://obrresurs.ru/science/pedagogy/monograf/2glava/

Osipova, G. V. (1990). Sociology and socialism. Moscow.

Pershins A.K. (2006). Legal bases of the border control authorities of the Federal Security Service. Moscow, 228.

Prokhozhev, A. A. (2002). Man and society: the laws of social development and security. Moscow, 171.

Shtompka, P. (2005). Sociology. Analysis of modern society (C. M. Chervonnaya). Moscow: Logos, 664.

Smirnov, A. T, Shakhramanyan, M. A. \& Kryuchek, N.A. (2009). Health and Safety. Moscow, 375.

Subetto, A. I. (1997). Revolution of vernadsky, nonclassical ecology and environmental education in Russia (C.B. Alexeev). St.Petersburg: Christmas, 9-10.

Telegina N.V., Galimova E.G \& Masalimova A.R. (2015).The Structure and Content of the Model of Pedagogical Conditions Binary Approach to Optimization of Control and Diagnostic Functions in Teaching "General pedagogy" to Students. Asian Social Science, Vol. 11, No. 1, 364-368, doi:10.5539/ass.v11n1p364.

Ursula, A. D. (1996) Science and education in sustainable development strategies (S. N. Glazacheva). Volgograd: Change, 7-13. Vasilyeva, A. I. (1999). The system of national security of the Russian Federation (Doctoral dissertation). Sciences. St. Petersburg. Waltz, K., \&Walt, S. M. (1985). Alliance Formation and the Balance of World Power. International Security: 4.

Yakupov, A. M. (2007). Transport and school culture conditions of its formation. Magnitogorsk: Magnitogorsk State University, 283. 